\title{
Quality of Varieties of Spring Soft Wheat Grain and their Ranking for Baking Strength
}

\author{
Letyago Yulia Alexandrovna \\ Associate Professor of the Department of Food Technology \\ Federal State Budgetary Educational \\ Institution of Higher Education \\ «Northern Trans-Ural State Agricultural University», \\ Tyumen, Russia \\ 77720143684@mail.ru
}

\author{
Belkina Raisa Ivanovna \\ Professor, Department Technologies of production, storage \\ and processing of crop, \\ Federal State Budgetary Educational \\ Institution of Higher Education \\ «Northern Trans-Ural State Agricultural University», \\ Tyumen, Russia \\ raisa-medvedko@mail.ru
}

\begin{abstract}
The article presents the results of the determination of the index (the ratio of the actual indicator to the standard for strong wheat) of the nature of the grain, the mass fraction of gluten in the grain, the strength of the flour, the bread volume and the overall baking evaluation for wheat varieties differing in baking strength: strong wheat varieties not related to the strong and valuable. It was found that the grain index of the above groups of varieties was within 0.98-1.00. A high index of the mass fraction of gluten in the grain characterized a variety of strong wheat Novosibirsk 15 (1.26), valuable - Tyumen 25 (1.17), as well as Tyumen $26(1.22)$. There were significant differences in the magnitude of the strength of flour for groups of varieties. On average, over the years of research, the average index for varieties of strong wheat was $\mathbf{1 . 1 0}$, for varieties of valuable wheat - 1.03, in the group of varieties not related to the strong and valuable - 0.86. Assessment of varieties according to the index of individual characteristics allows them to be ranked in accordance with the quality level.
\end{abstract}

Keywords - wheat varieties, nature, gluten, strength of flour, quality index

\section{INTRODUCTION}

The requirements of the national wheat standard include five classes.

The norms of the first and second classes are valid for the grain of strong wheat, the third on the valuable wheat, the fourth grade wheat refers to the food grade, the fifth to the fodder. The Central Laboratory of the State Commission for Testing and Preservation of Selection Achievements classifies wheat varieties according to a number of indicators, including the rheological properties of the dough and the results of laboratory bread baking. In accordance with this classification, "strong wheat-improvers", "most valuable in quality", "wheatfillers" and "weak wheat" are distinguished [1]

When cultivating strong and valuable wheat in production, they do not always retain a high potential for grain quality. It is inadvisable to orient technologies on the production of strong wheat, since the grain market, especially the outside one, requires relatively cheap wheat of low quality. In this regard, there was a situation of a decline in the quality indicators of wheat grown in the country [2].

At the same time, high-quality raw materials for flour and bread production are necessary, since traditionally bread for the population of our country constitutes a significant share in food products. In increasing the production of high-quality wheat grains, the variety's role is very significant [3]. Reliable production of such grains can be guaranteed when growing varieties sufficiently stable form high technological properties at the level of the requirements of the current standard. In the opinion of S.S. Sinitsyn [4], the main criterion for the quality of grain of new varieties is the frequency of formation of strong grains by all indicators. Meanwhile, a number of researchers note that varieties cultivated in Siberia do not always form a stable quality of grain at the level of the requirements of existing standards $[5,6]$. In addition, except the reducing of the technological indicators, some varieties tighten maturation, can sprout in the ear and become infected by diseases, all these limit the stable production of highquality wheat.

For the conditions of the Northern Trans-Urals, a classification of wheat varieties into groups has been developed taking into account the purpose of the grain. The first group includes varieties that meet the quality requirements for strong wheat, the second group includes varieties that steadily form grain that meets the standards for valuable wheat. The third group is represented by varieties of the average quality level, which are not stable enough to form grain within the limits of standards for valuable, in the fourth group - high-yielding varieties of wheat, the grain of which is expedient for use for fodder purposes. The notion of "food value" of the wheat variety is considered. The ability to form grain in a particular region in accordance with the requirements for strong and valuable wheat [7].

For the purpose of comparative analysis of wheat varieties by technological indicators, relative values are used $[4,8]$. Qualimetry applies a coefficient that allows you to assess the level of product quality by comparing the actual value of the indicator with the normative one. The quality factor is used for a comprehensive assessment of wheat varieties in the northern 
forest-steppe of the Tyumen region. As a result, varieties were identified that most consistently form high technological properties of grain: Novosibirskaya 15, Irgina, Zlatozar, Irene [9].

The purpose of our research is to study the possibility of applying a quality factor (quality index) for the evaluation of wheat varieties differing in baking strength..

\section{SUBJECTS AND METHODS}

The research and field experiments were carried out in 2010-2012 on the basis of the Agrotechnological Institute of the Northern Trans-Ural State Agricultural University (the zone of the northern forest-steppe of the Tyumen region). Laboratory studies were carried out in the laboratories of the Agrobiotechnological Center of the Northern Trans-Ural State Agricultural University and the Kurgan Scientific Institute of Agriculture.

The soil of the experimental field is leached chernozem, heavy loam and predecessor - annual grasses. Fertilizers were applied in terms of grain yields of 4 tons / ha. Soil cultivation is generally accepted for culture in the zone. The area of the plot is $15 \mathrm{~m} 2$ with 4 replication and complete randomization.

Objects of research: varieties of strong wheat Novosibirskaya 15, Novosibirskaya 29, SKENT-1; valuable Irene, Omsk 36, Krasnoufimskaya 100, Lutescens 70, Tyumen 25; varieties that do not belong to the strong and valuable, the selection of the Scientific Institute of Agriculture of the Northern Trans-Urals: Ricks, Adeline, Tyumenskaya 26, Kazakhstani early.

Observations and accounting in field experiments were carried out according to the methodology of the State Commission for Variety Testing (1985).

Indicators of grain quality are determined in accordance with the methods set out in government standards. The index of the quality of the trait was calculated by the ratio of the actual indicator to the normative one, established for strong wheat: grain nature - $750 \mathrm{~g} / \mathrm{l}$; gluten content in grain - 28\%; strength of flour - 280 e.a.; the volume of bread is $1200 \mathrm{~cm} 3$, the total baking score is 4.5 points.

\section{RESULTS AND DISCUSSION}

The meteorological conditions of 2010 for air temperature and humidity were slightly different from the average multiyear level. 2011 was characterized by a moderate air temperature throughout the growing season, excessive moistening in June and a lack of precipitation in the second half of the growing season. In general, this year conditions were favorable for the growth and development of plants and the formation of productivity of spring wheat varieties. In 2012, there was hot and dry weather with a deficit of rain during the growing season - this negatively affected the yield of wheat varieties and promoted the formation of grains with a high content of gluten.

One of the most important features that characterize the physical properties of grain is nature. The value of this indicator depends on the yield of flour and cereals during grain processing [10, 11]. Largely, nature depends on the genetic characteristics of varieties. The better the grain, the higher its density, the higher the grain nature, the more products you can get when processing it. A higher nature is formed under favorable conditions of moistening and temperature during the filling and ripening of the grain.

Judging by the index, the arid conditions of 2012 adversely affected the magnitude of nature (Table 1). In most varieties, the index is less than one. In 2011 and 2012, most varieties have formed a nature within requirements of 1 st class of the State Standart - the index is greater than one.

TABLE I. INDEX OF GRAIN IN WHEAT VARIETIES

\begin{tabular}{|c|c|c|c|}
\hline Varieties & $\mathbf{2 0 1 0}$ g. & $\mathbf{2 0 1 1}$ g. & $\mathbf{2 0 1 2}$ g. \\
\hline \multicolumn{4}{|c|}{ Strong wheat } \\
\hline Novosibirskaya 15 & 1.00 & 0.98 & 0.93 \\
\hline Novosibirskaya 29 & 0.98 & 1.02 & 0.94 \\
\hline SKENT-1 & 0.95 & 1.01 & 0.95 \\
\hline \multicolumn{3}{|c|}{ Valuable wheat } \\
\hline Iren & 1.00 & 1.01 & 0.92 \\
\hline Omskaya 36 & 1.02 & 1.04 & 0.90 \\
\hline Krasnoufimskaya 100 & 1.01 & 1.01 & 0.88 \\
\hline Lutescens 70 & 1.05 & 1.00 & 0.91 \\
\hline Tyumenskaya 25 & 1.04 & 1.05 & 0.96 \\
\hline Varieties not related to strong and valuable \\
\hline Riks & 1.03 & 0.98 & 0.97 \\
\hline Adelina & 1.05 & 1.04 & 0.95 \\
\hline Tyumenskaya 26 & 1.03 & 1.02 & 0.96 \\
\hline Kazakhstanskaya early & 0.99 & 1.00 & 1.02 \\
\hline
\end{tabular}

On average, for the years of research in the varieties of strong wheat, the index of nature was 0.98 , for varieties of valuable wheat -0.99 , for varieties not related to strong and valuable - 1.00 .

Gluten of wheat is the main attribute on which the quality of bread depends. The amount of gluten, its mass fraction are conditioned by the genotype and heavily influenced by environmental conditions [12, 13, 14, 15]. The index of the mass fraction of gluten was the highest in varieties in 2012, which can be explained by the increased air temperature during the ripening period. In the case of varieties of strong wheat, the index value in this year was 1.12-1.45, with an average value of 1.32 ; in varieties of valuable wheat, these figures corresponded to 1.13-1.36 and 1.22; in other varieties 0.99-1.46 and 1.17 (Table 2).

Among the varieties of strong wheat, the high index of the mass fraction of gluten was characterized by Novosibirsk 15 on average over the years of research - 1.26. Of the group of valuable wheat, Tyumen $25-1.17$ from the group of other varieties - Tyumenskaya 26 - 1.22 - stood out. 
TABLE II.

INDEX OF THE MASS FRACTION OF RAW GLUTEN IN WHEAT GRAINS

\begin{tabular}{|c|c|c|c|}
\hline Varieties & 2010 g. & 2011 g. & 2012 g. \\
\hline \multicolumn{4}{|c|}{ Strong wheat } \\
\hline Novosibirskaya 15 & 1.23 & 1.10 & 1.45 \\
\hline Novosibirskaya 29 & 1.18 & 1.04 & 1.39 \\
\hline SKENT-1 & 1.01 & 0.78 & 1.12 \\
\hline \multicolumn{4}{|c|}{ Valuable wheat } \\
\hline Iren & 1.15 & 1.13 & 1.17 \\
\hline Omskaya 36 & 1.10 & 1.10 & 1.13 \\
\hline Krasnoufimskaya 100 & 0.99 & 1.07 & 1.22 \\
\hline Lutescens 70 & 1.21 & 1.00 & 1.22 \\
\hline Tyumenskaya 25 & 1.05 & 1.11 & 1.36 \\
\hline Varieties not related to strong and valuable \\
\hline Riks & 1.07 & 0.78 & 1.16 \\
\hline Adelina & 1.07 & 0.88 & 1.09 \\
\hline Tyumenskaya 26 & 1.04 & 1.17 & 1.46 \\
\hline Kazakhstanskaya early & 1.03 & 1.04 & 0.99 \\
\hline
\end{tabular}

The strength of the flour, determined on the alveograph, is one of the main indicators of the physical properties of the dough. The standard for strong wheat in this indicator is not less than 280 ea. The highest indicators of the strength of flour and, consequently a high index of this feature are noted in varieties of strong wheat (Table 3 ). The maximum value of the index of Novosibirsk 15 in 2012. - 1.45 on the average for years of research -1.24 .

Among the varieties of valuable wheat Irene stood out, its indicators corresponded to: 1.26 and 1.21. In the group of other varieties, the best characteristics were Tyumen 26: the maximum index was 1.17 , the average for the years of study was 1.11 . There are significant differences in the magnitude of the strength of flour for groups of varieties. On average, over the years of research, the average index for varieties of strong wheat was 1.10 , for varieties of valuable wheat -1.03 , in the group of other varieties -0.86 .

According to the results of laboratory bread baking, two main indicators are standardized: bread volume (standard for strong wheat $1200 \mathrm{~cm} 3$ ) and total baking mark (4.5 points). Varieties of strong wheat differed from other varieties by a higher index of bread volume. In 2010, the average indices for varieties in the groups were: $1.01 ; 0.76 ; 0.76$; in $2011-0.64$; 0.57 ; 0.61 ; in $2012-1.16 ; 0.86 ; 0.82$ (Table 4 ).
TABLE III. INDEX OF STRENGTH OF FLOUR IN WHEAT VARIETIES

\begin{tabular}{|c|c|c|c|}
\hline Varieties & $2010 \mathrm{~g}$. & $2011 \mathrm{~g}$. & $2012 \mathrm{~g}$. \\
\hline \multicolumn{4}{|c|}{ Strong wheat } \\
\hline Novosibirskaya 15 & 1.60 & 1.00 & 1.12 \\
\hline Novosibirskaya 29 & 1.15 & 1.12 & 1.21 \\
\hline SKENT-1 & 1.12 & 0.53 & 1.05 \\
\hline \multicolumn{4}{|c|}{ Valuable wheat } \\
\hline Iren & 1.26 & 1.06 & 1.32 \\
\hline Omskaya 36 & 0.80 & 0.79 & 0.76 \\
\hline Krasnoufimskaya 100 & 0.91 & 0.73 & 1.25 \\
\hline Lutescens 70 & 1.57 & 0.83 & 1.07 \\
\hline Tyumenskaya 25 & 1.05 & 0.88 & 1.13 \\
\hline \multicolumn{4}{|c|}{ Varieties not related to strong and valuable } \\
\hline Riks & 0.53 & 0.73 & 0.97 \\
\hline Adelina & 1.13 & 0.92 & 0.75 \\
\hline Tyumenskaya 26 & 1.17 & 1.01 & 1.15 \\
\hline Kazakhstanskaya early & 0.69 & 0.45 & 0.78 \\
\hline
\end{tabular}

TABLE IV. . INDEX OF BREAD VOLUME FROM $100 \mathrm{G}$ OF FLOUR FOR WHEAT VARIETIES, CM3

\begin{tabular}{|c|c|c|c|}
\hline Varieties & $2010 \mathrm{~g}$. & $2011 \mathrm{~g}$. & $2012 \mathrm{~g}$. \\
\hline \multicolumn{4}{|c|}{ Strong wheat } \\
\hline Novosibirskaya 15 & 1.29 & 0.80 & 1.29 \\
\hline Novosibirskaya 29 & 1.04 & 0.72 & 1.25 \\
\hline SKENT-1 & 0.69 & 0.4 & 0.94 \\
\hline \multicolumn{4}{|c|}{ Valuable wheat } \\
\hline Iren & 0.85 & 0.62 & 0.84 \\
\hline Omskaya 36 & 0.46 & 0.37 & 0.60 \\
\hline Krasnoufimskaya 100 & 0.91 & 0.59 & 1.13 \\
\hline Lutescens 70 & 0.77 & 0.52 & 0.72 \\
\hline Tyumenskaya 25 & 0.71 & 0.73 & 1.02 \\
\hline \multicolumn{4}{|c|}{ Varieties not related to strong and valuable } \\
\hline Riks & 0.74 & 0.88 & 1.03 \\
\hline Adelina & 0.66 & 0.57 & 0.83 \\
\hline Tyumenskaya 26 & 0.65 & 0.47 & 0.77 \\
\hline $\begin{array}{c}\text { Kazakhstanskaya } \\
\text { early }\end{array}$ & 0.60 & 0.51 & 0.63 \\
\hline
\end{tabular}


On average, over the years of research from the varieties of strong wheat, the Novosibirsk 15 (index 1.13), from the varieties of valuable wheat - Krasnoufimskaya 100 (index 0.88 ), from the group of other varieties - Ricks (index - 0.88).

The index of the general bakery assessment on average over the years of research varied according to varieties of strong wheat from 0.75 to 0.95 , in varieties of valuable wheat - from 0.62 to 0.84 , in other varieties - from 0.70 to 0.80 . The highest value of the index in the variety Novosibirskaya 15 (0.95).

Thus, the assessment of varieties according to the index of individual characteristics allows them to be distributed within groups in accordance with the quality level. For example, on the basis of the mass fraction of gluten, varieties of strong wheat are distributed as follows: 1 - Novosibirsk 15.

\section{CONCLUSION}

1. The index of the grain's nature for groups of varieties differing in baking strength was within 0.98-1.00.

2. A high index of the mass fraction of gluten in grain was from variety of strong wheat Novosibirskaya 15 (index on average for the years of research 1.26), valuable - Tyumenskaya 25 (1.17), and Tyumen 26 (1.22).

3. There are significant differences in the magnitude of the strength of flour for groups of varieties. On average, over the years of research, the average index for varieties of strong wheat was 1.10 , for varieties of valuable wheat - 1.03, in the group of varieties not related to the strong and valuable -0.86 .

\section{References}

[1] T. V. Gorpinchenko, "Assessment of quality of varieties of agricultural crops as raw materials for processing”, Moscow, 2008, p. 151.

[2] E. P. Meleshkina, "Quality of Russian grain of wheat: dynamics, features and problems", Proc. of the 13th All-Russian Scientific and
Practical Conference, June 06-10, 2016, Anapa, pp. 4-9 [Modern methods, tools and standards in the field of assessing the quality of grain and grain products, 2016, Anapa]

[3] V.B. Sobyanin, O.V. Volynkina, "The role of cultivar and cultivation technology in increasing the collection of high-quality wheat", Proc. of Int. Scientific-Practical Con. dedicated to the 110th anniversary of the birth of T.S. Malcev, 2006, pp. 159-162 [The role of modern technologies in the sustainable development of the agroindustrial complex, Kurgan: Publishing house "DAMMI", 2006].

[4] S. S. Sinitsyn, "A System Approach to Solving the Problem of the Quality of Wheat Grain”, Herald of Agricultural Science, 1987, № 7. P. 53-59.

[5] N. G. Vedrov, I. V. Pantyukhov, "Selective problems of increasing the quality of spring wheat in Eastern Siberia", Selection of agricultural crops: results, tasks, solutions, Novosibirsk, 1997, pp. 17-18.

[6] T. A. Kozlova, "Productivity and quality of grain of spring wheat varieties depending on soil - climatic zones of cultivation of Zauralye", The agrarian messenger of the Urals, 2010, vol. 72, No. 6, pp. 39-41.

[7] R. I. Belkina, Yu. A. Letyago, "Rational use of grains of varieties of strong and valuable wheat in the Northern Trans-Urals", News of the Orenburg State Agrarian University, Orenburg, 2017, vol. 67, No. 5, pp. 19-21.

[8] A. S. Ivanenko, "The problem of grain quality in the Tyumen region and possible ways to solve it", OMSCI, Omsk, 1993, p. 36

[9] R.I. Belkina, T.S. Akhtaryeva, D.I. Kucherov, M.I. Maslenko, A.A Savchenko, K.V. Moiseyev, "Productivity and grain quality of spring soft wheat in the Northern Trans-Urals", Tyumen: Publishing house "Titul", 2017, 188 p.

[10] I. Hlinka, W. Bushuk, "The weight per bushel”, Cereal Sci. Today, No, 4, 1959, pp. 239-240.

[11] Yu.V. Kolmakov, L.A. Zelova, A.A. Timoshkin, "Factors causing qualitative wheat grain", Siberian scientists - agro-industrial complex, Omsk: Siberian Research Institute, 2000, pp. 21-23.

[12] M.I. Knyaginichev, "Quality of wheat grain, depending on the variety and growing conditions", Biochemistry of wheat, Moscow-Leningrad. Sel'khozhiz, 1951, p. 272

[13] A.Vakar, "Gluten of wheat", Moscow: Publishing House of the Academy of Sciences of the USSR, 1961, p. 252.

[14] V.V. Schneider, "Increase the value of spring wheat", Grain economy, 1985, No. 6, pp. 16-17.

[15] I.E. Lihenko, N.N. Lihenko, "Biological features of spring soft wheat in the conditions of the northern forest-steppe of Western Siberia and their use in breeding", Novosibirsk: Siberian Division of the Russian Academy of Agricultural Sciences, 2007, p. 224 